\title{
Analyzing the Image of the Right People in the Leading Domestic Companies of South Korea
}

\author{
Ji-Hye Bae ${ }^{1}$ and Young-Min Lee ${ }^{2 *}$ \\ ${ }^{1}$ Graduate School of the Department of Education, Kyungpook National University, \\ Sangyeok 3-dong, Buk-gu, Daegu, Korea \\ ${ }^{2}$ Graduate School of Human Resource Developments for Women, \\ Sookmyung Women's University, Yongsan-gu, Seoul, Korea \\ ${ }^{1}$ heybjh@gmail.com, ${ }^{2 *}$ ymlee@sookmyung.ac.kr
}

\begin{abstract}
The image of the right people of domestic leading enterprise has been constantly changing. In the 1960s, businesses preferred talent who had a strong sense of responsibility and diligence. But now in human resources the preference is for those who have profound knowledge and problem solving skills. To analyze image of qualified employee of leading domestic companies, we conducted an analysis on the top 100 businesses using the $R$ statistical software and a correspondence analysis. After extracting the keywords related to the ideal traits of human resources through the $R$-statistic, we carried out a frequency analysis on each of the extracted keywords. Twenty-three keywords of the right people's factor were proposed through the extraction and merge processes. We performed a cross analysis by setting up the keywords as independent variables while fixing the business type, total assets, operating profits, and area as dependent variables and conducted a correspondence analysis based on the results of the cross analysis to produce graphs to visualize possible similarities between variables. As a result, business environment, such as area and business type, influenced the formulating of an image of a qualified employee. Construction, banking, securities, and financial holding companies prefer human resources with the elements of creativity, passion, openness, and self-directedness. Furthermore, companies having more than $\$ 16$ billion, but less than $\$ 32$ billion of total assets, pursue creativity, morality, and interaction as factors of the right people.
\end{abstract}

Keywords: Right people, Qualified employee, Human resources, Correspondence analysis

\section{Introduction}

The perception of qualified candidate has been undergoing constant alterations because of the rapidly changing business environments. When South Korea started becoming industrialized in the 1960s, companies were in need of the so-called supporters who had a strong sense of "responsibility" and "diligence." In the 1970s, "activeness" and "interaction" have surfaced as new keywords in terms of the ideal traits of employees. As South Korean society entered a stable growth period in the 1980s, there was a strong need among people to share the success of the economy. While previous ideal traits, such as faithfulness and activeness, were still considered, new ideal features of employees emerged, such as mission and professionalism. When the nation jumped on the bandwagon of global competition in the 1990s, the ideal traits of a qualified candidate were regarded as a "challenging spirit," "motivation," "creativity," "specialty," and "insight." In the

${ }^{*}$ Corresponding Author 
2000s, companies were scrambling to recruit those who had in-depth knowledge in their own specialty and were also armed with broad common knowledge in various fields [1]. Furthermore, convergence-minded people have come into the limelight in recent years, going beyond the simple expansion of knowledge, transcending barriers between disciplines, and trying to solve problems from diverse viewpoints.

In previous studies, if companies are classified as a competitive power, the leading chasers demanded the total designer, innovators demanded the problem solver, and late chasers demanded the traditional humanity. An operational definition of "total designer" is a talented person who has the special characteristics of work, conceptual and logical thinking, troubleshooting ability, and leadership. For a problem solver an operational definition is people who capably administer for the company based on skilled job performance. Lastly. "traditional humanity" means traditional characteristics such as a sense of morality and etiquette [2].

Other studies on the image of a qualified employee in South Korean companies extracted the top ten keywords from a website of companies in the top 300 based sales. The top ten keywords are: creativity, specialty, challenging spirit, global capabilities, cooperation, passion, customer-oriented, innovation, change, and responsibility [3]. In another study, the researcher determined that most of the properties of the right person related to a sociotropic element with technical analysis. Most companies want to recruit an interpersonal person who is investigative, customer-oriented, and is cooperative. Namely, capabilities of the relationship occupied a high priority in building the image of a qualified employee [4].

Because of changes in the types of a qualified employee, a company should develop a strategy about recruitment and its human resource management system. Jo and Lee stated that the company needs to make an effort to associate the "image of qualified employee" and their HR system through a combination of core competencies and job tasks. In other words, to achieve the goals of both the organization and the individual an integrated system is needed for not only the recruiting of the right people but also maintaining and training them [5].

Consequently, more diversified analytic approaches are needed to respond to the changing needs of the time and to flexibly cope with changes. Whereas previous studies focused on the ideal traits of employees, this study aimed to carry out a correspondence analysis of the top 100 businesses by analyzing the correlation of their preferred traits for an employee with the type of business, total assets, sales and operating incomes, in order to identify the future human resources features. The research questions are: What are the images of a qualified employee of leading companies? And what other specific characteristics can be classified as the result of correspondence analysis?

\section{Research Methods}

First, we extracted keywords in relation to the ideal features of employees preferred by the top 100 domestic businesses in South Korea. To calculate the sales volumes of the analysis object groups, the following were used: the year-end settlement data of the top 1000 businesses from Korchambiz (http://www.korchambiz.net/) run by the South Korean Chamber of Commerce and Industry, and the KOPSI domestic trading market data provided by Finance Information of NAVER, which is a South Korean portal site. Then, we visited the official websites of the top 100 businesses to collect keywords in relation to their preferred traits for prospective employees and narrowed down the list of the selected keywords through a text-mining technique by using the $\mathrm{R}$ program. A text-mining technique is a method of processing atypical data, such as MS Word, e-mail, presentations, spreadsheets, and PDF file formats into data that meet specific forms and conditions, and it is useful for extracting keywords to predict a future trend and as a quantitative data analysis tool to supplement the qualitative data of experts [6]. Before we started to analyze 
the ideal features of human resources, we converted phrases contained in the statements on their homepages into text files in the UTF-8 format, extracted keywords using the R program, and analyzed the frequency and correlation of the keywords. In order to present the extracted keywords in a maximally integrated manner, we minimized the semantically identical keywords on the basis of the one-on-one Behavioral Event Interview (BEI) by a panel of experts and the thematic analysis method [7].

Second, a correspondence analysis was conducted using the SPSS ver. 18, a statistical analysis package program. Since the 1980s, correspondence analysis has been commonly utilized for the homogeneity analysis, non-linear principal component analysis, and multivariate analysis, and is a type of statistical downscaling methodology to analyze the specific relation between categories by expressing dependent and independent variables as points on the intersecting space of rows and columns [8]. After extracting the keywords related to the ideal traits of human resources, we carried out a frequency analysis on each of the extracted keywords, performed a cross analysis by setting up the keywords as independent variables while fixing the sales volumes, total assets, operating incomes, sales fluctuations, and operating fluctuations as dependent variables, and conducted a correspondence analysis based on the results of the cross analysis to produce graphs to visualize possible similarities between the variables.

\section{Results}

\subsection{The Right People's Features of South Korean Domestic Businesses}

After the command "(extractNoun, USE.NAMES=F)" to extract keywords from the websites of the top 100 South Korean domestic businesses through the textmining method of the $\mathrm{R}$ program, we carried out a frequency analysis by inputting the commands in the following order: (1) talent<-read.csv ("talent.csv", header=TRUE), (2) install.packages("descr"), (3) library(descr), (4) freq(talent\$talenton-demand).

After conducting an analysis of the top 30 businesses, it was found that the 5 highest ranking features of the right people were Challenging spirits (23), Specialty (14), Morality (13), Creativity (10), and Cooperation (10) [9]. In contrast to this, the results of the analysis of the top 100 South Korean domestic businesses showed that the highest ranking was a Challenging spirit (78), followed by Cooperation (76), and Creativity (60), which accounted for $13 \%, 12 \%$, and $10 \%$, respectively, of the entire extracted keywords. Apart from it, Innovation (49), Morality (45), and Passion (44), respectively, took up more than $7 \%$.

Among 23 factors of right people, most of the factors except for the specialty, global talent and insight are related to human nature. This fact is a circumstantial evidence that humanity cannot change easier than technical skills which can be trained. Therefore companies tend to prefer attitude to skills.

Table 1. Frequency Analysis of Keywords of the Right People

\begin{tabular}{|c|c|c|c|c|c|}
\hline Keyword of the right people & Frequency & Percent & Keyword of the right people & Frequency & Percent \\
\hline Challenging spirit & 78 & $13 \%$ & Global talent & 17 & $3 \%$ \\
\hline Cooperation & 76 & $12 \%$ & Self-improvement & 17 & $3 \%$ \\
\hline Creativity & 60 & $10 \%$ & Immersion & 16 & $3 \%$ \\
\hline Innovation & 49 & $8 \%$ & Value creation & 15 & $2 \%$ \\
\hline Morality & 45 & $7 \%$ & Customer respect & 11 & $2 \%$ \\
\hline
\end{tabular}




\begin{tabular}{|c|c|c|c|c|c|}
\hline Passion & 44 & $7 \%$ & Faithfulness & 6 & $1 \%$ \\
\hline Specialty & 35 & $6 \%$ & Insight & 6 & $1 \%$ \\
\hline Responsibility & 32 & $5 \%$ & Positive attitude & 5 & $1 \%$ \\
\hline Openness & 30 & $5 \%$ & Savings & 2 & $0 \%$ \\
\hline Interaction (Communication) & 27 & $4 \%$ & Potential & 1 & $0 \%$ \\
\hline Activeness & 27 & $4 \%$ & Etiquette & 1 & $0 \%$ \\
\hline Self-directedness & 22 & $4 \%$ & Total & $\mathbf{6 2 2}$ & $\mathbf{1 0 0 . 0} \%$ \\
\hline
\end{tabular}

\subsection{Results of the Correspondence Analysis}

The cross analysis was carried out in consideration of the relations of total assets and operating profits after classifying the types of companies by business type and dividing the regions into Seoul ("special city"), Incheon and Gyeonggi Province, Honam and Chungcheong Province, and Yeongnam Province. The numerical contents of the cross analysis were reinterpreted through correspondence analysis in consideration of the significance levels, and the results were diagramed on a 2D plane to visualize the correlation between categories and the density between variables.

The categories of rows are as follows: 1-Challenging spirit, 2-Cooperation, 3Creativity, 4-Innovation, 5-Morality, 6-Passion, 7-Specialty, 8-Responsibility, 9 Openness, 10-Interaction(Communication), 11-Activeness, 12-Self-directedness, 13 Global talent, 14-Self-improvement, 15-Immersion, 16-Value creation, 17-Customer respect, 18-Faithfulness, 19-Insight, 20-Positive attitude, 21-Savings, 22-Potential, 23-Etiquette. The categories of the columns were classified as follows: 1Construction, 2-Distribution, 3-Manufacturing, 4-Banking, Securities and Financial Holding Companies, 5-Others.

First, to look into the correlation between a business type and talent, we converted frequency count into a profile of rows and a profile of columns. The profile of rows is the relative ratio divided by separating the factor of the right people by the sector of industry. Around an activist is the sum of all profile values in the column. The profile of columns is the relative ratio divided by the sector of industry by the sum of the factor of the right people.

Table 2. Profile of Rows

\begin{tabular}{|c|c|c|c|c|c|c|c|c|c|c|c|}
\hline $\begin{array}{c}\text { talent } \\
\text { sectok }\end{array}$ & 1 & 2 & 3 & 4 & 5 & 6 & 7 & 8 & & 21 & $\begin{array}{c}\text { around } \\
\text { an } \\
\text { activist }\end{array}$ \\
\hline 1 & .162 & .054 & .135 & .054 & .108 & .054 & .081 & .081 & & .000 & 1.000 \\
2 & .108 & .117 & .099 & .063 & .054 & .072 & .072 & .090 & & .000 & 1.000 \\
3 & .131 & .097 & .128 & .087 & .072 & .075 & .053 & .044 & & .003 & 1.000 \\
4 & .127 & .089 & .139 & .063 & .089 & .063 & .051 & .025 & & .000 & 1.000 \\
5 & .100 & .088 & .100 & .125 & .075 & .113 & .063 & .038 & & .000 & 1.000 \\
average & .124 & .096 & .121 & .083 & .073 & .076 & .059 & .051 & & .002 & \\
\hline
\end{tabular}


Table 3. Profile of Columns

\begin{tabular}{|c|c|c|c|c|c|c|c|c|c|c|c|}
\hline $\begin{array}{c}\text { talent } \\
\text { sector }\end{array}$ & 1 & 2 & 3 & 4 & 5 & 6 & 7 & 8 & & 21 & $\begin{array}{c}\text { avera } \\
\text { ge }\end{array}$ \\
\hline 1 & .077 & .033 & .066 & .038 & .087 & .042 & .081 & .094 & & .000 & .059 \\
2 & .154 & .217 & .145 & .135 & .130 & .167 & .216 & .313 & & .000 & .177 \\
3 & .538 & .517 & .539 & .538 & .500 & .500 & .459 & .438 & & 1.000 & .511 \\
4 & .128 & .117 & .145 & .096 & .152 & .104 & .108 & .063 & ellipsi & .000 & .126 \\
5 & .103 & .117 & .105 & .192 & .130 & .188 & .135 & .094 & & .000 & .127 \\
$\begin{array}{c}\text { around } \\
\text { an } \\
\text { activist }\end{array}$ & 1.000 & 1.000 & 1.000 & 1.000 & 1.000 & 1.000 & 1.000 & 1.000 & & 1.000 & \\
\hline
\end{tabular}

The number of dimensions is in Table 4, which subtracts 1 from the smaller number of a row or column. Dimension 1 had an inertia value of 0.037 and an interpretability value of about 53\%, while Dimension 2 showed an inertia value of 0.013 and an interpretability value of about $19.5 \%$. Dimensions 3 and 4 have inertia values of 0.011 and 0 ., respectively, and interpretability values of $16.5 \%$ and $10.7 \%$, respectively. The Chi-square value was measured at 43.027 , while $p<0.10$ appeared at the degree of freedom of 80 .

Table 4. Description of Dimensions

\begin{tabular}{|c|c|c|c|c|c|c|c|c|}
\hline \multirow[b]{2}{*}{ Dimensions } & \multirow[b]{2}{*}{$\begin{array}{l}\text { Eigen } \\
\text { value }\end{array}$} & \multirow[b]{2}{*}{$\begin{array}{l}\text { Inertia } \\
\text { value }\end{array}$} & \multirow[b]{2}{*}{$\begin{array}{l}\text { Chi- } \\
\text { square } \\
\text { value }\end{array}$} & \multirow[b]{2}{*}{$\begin{array}{l}\text { significance } \\
\text { probability }\end{array}$} & \multicolumn{2}{|c|}{ consistency ratio } & \multicolumn{2}{|c|}{ Reliability Eigen value } \\
\hline & & & & & interpretability & cumulative & $\begin{array}{l}\text { standard } \\
\text { deviation }\end{array}$ & \begin{tabular}{|c|}
$\begin{array}{c}\text { correlation } \\
\text { coefficient }\end{array}$ \\
2
\end{tabular} \\
\hline 1 & .191 & .037 & & & .533 & .533 & .040 & -.010 \\
\hline 2 & .116 & .013 & & & .195 & .728 & .036 & \\
\hline 3 & .106 & .011 & & & .165 & .893 & & \\
\hline 4 & .086 & .007 & & & .107 & 1.000 & & \\
\hline total & & .069 & 43.027 & $1.000 \mathrm{a}$ & 1.000 & 1.000 & & \\
\hline
\end{tabular}

a. degrees of freedom: 80

It was found that talent 22: Potential and talent 23: Etiquette are considered important only in certain business fields. We also considered talent 18: Faithfulness and talent 19: Insight as outliers of this study. Figure 1 was redone after excluding these four factors of talent. 


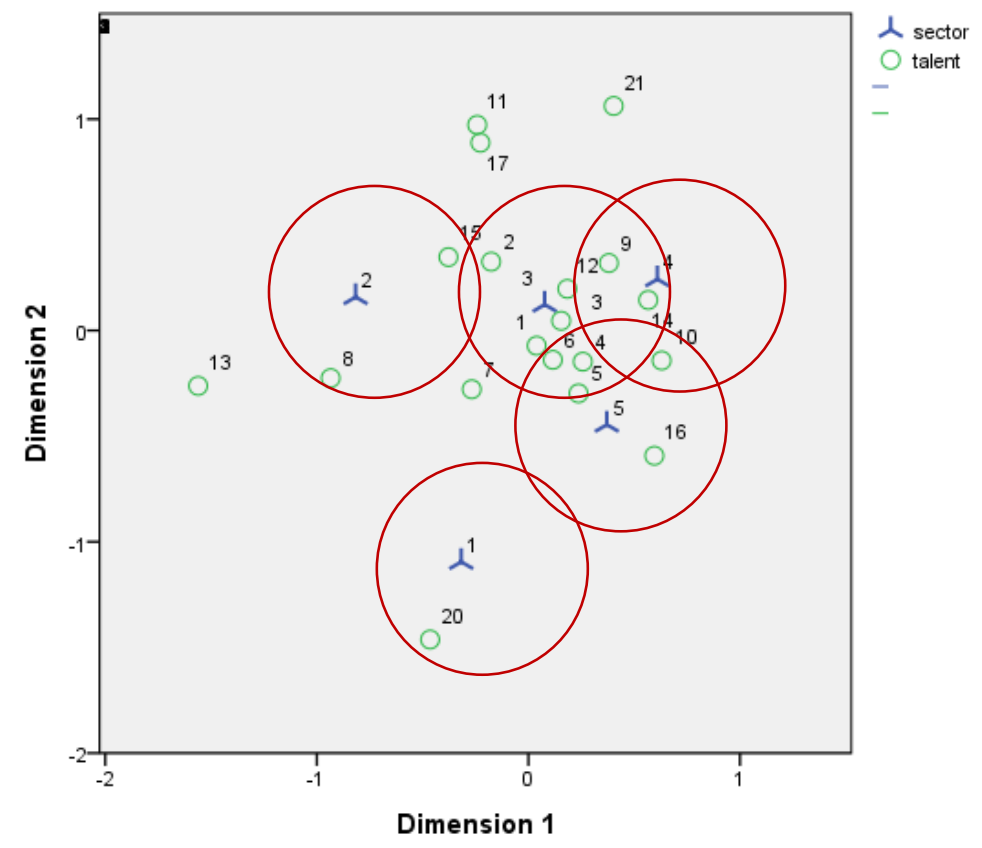

Figure 1. Correspondence Analysis Table between Sector and Talent

Occupying the center of Figure 1 are talent 1: Challenge spirit, 3: Creativity, and 2: Cooperation, which showed $0.124,0.121,0.096$, respectively, of a concordance rate (see Table 2). Looking at each sector, Talent 20: Positive attitude showed a comparatively high correspondence with the construction industry. And talent 8: Responsibility displayed a high concentration rate in distribution industry. Also talent 14; Self-improvement seems to correlate with banking, securities, and the financial companies industry. Finally, for sector 5: Others, there is a relatively strong association with talent 16: Value creation.

Looking at the common attribute, talent 15: Immersion appeared in both the distribution industry and manufacturing industry. There are 2 common factors, talent 9: Openness and talent 12: Self-directedness, between the manufacturing industry and banking, securities and financial holding companies industry. Likewise, talent 4: Innovation and talent 6: Passion has a profound relationship with the manufacturing industry and others.

Second, to look into the correlation between total assets and talent, we converted the frequency count into profile of rows and profile of columns. The total assets were classified into six categories: 1-below $\$ 4$ billion, 2-below $\$ 8$ billion, 3-below $\$ 16$ billion, 4-below $\$ 32$ billion, 5-below $\$ 80$ billion, 6-below $\$ 320$ billion. The rest of the procedure was the same as above, mutatis mutandis.

Dimension 1 had an inertia value of 0.033 and an interpretability value of about $33.2 \%$, whereas Dimension 2 showed an inertia value of 0.027 and an interpretability value of about $27.2 \%$. Also, Dimension 3 showed an inertia value of 0.021 and an interpretability value of about $21.2 \%$. Dimensions 4 and 5 , have inertia values of 0.014 and 0.004 , and interpretability values of $13.9 \%$ and about $0.5 \%$, respectively. The Chi-square value was measured at 60.241 , while $p<0.20$ appeared at the degree of freedom of 110 . 


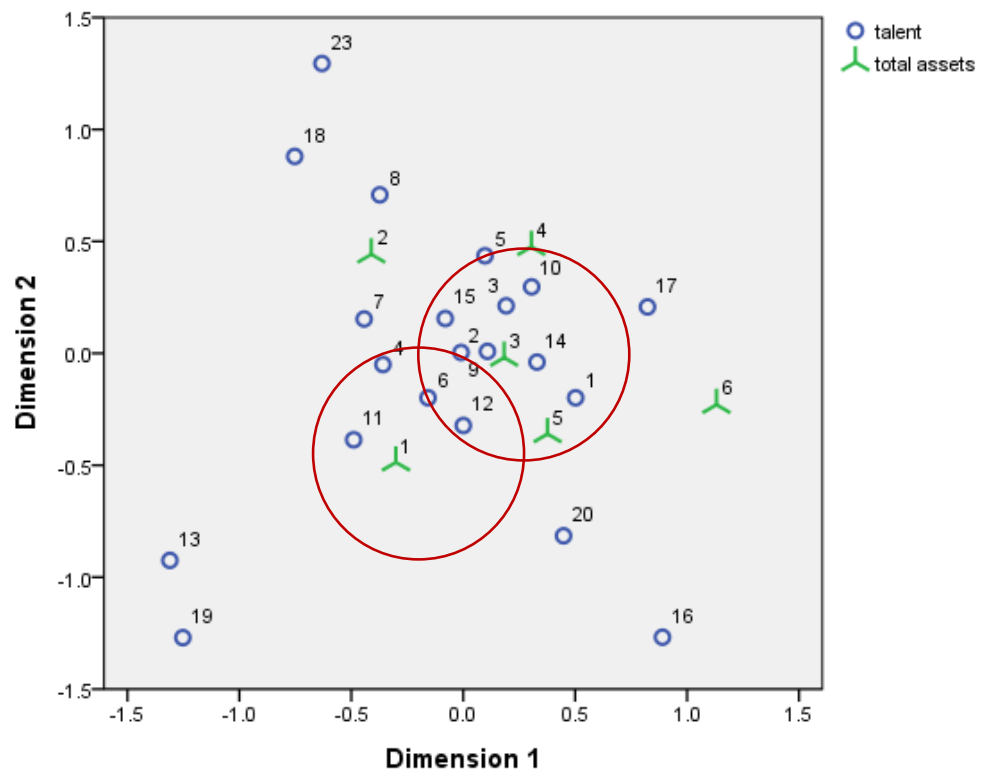

Figure 2. Correspondence Analysis Table between Total Assets and Talent

As shown in Figure 2 the companies of total assets of below $\$ 4$ billion preferred talent 4: Innovation, 6: Passion, 11: Activeness, 12: Self-directedness, as compared with other factors. Also, talent 8: Responsibility is related to total assets 2: below $\$ 8$ billion. Total assets 5: below $\$ 80$ billion has a profound relationship with talent 1: Challenging spirit. On the other hand, total assets 3-4: more than $\$ 8$ billion and below $\$ 32$ billion, showed a high correspondence with talents 2, 3, 5, 6, 9, 10, 12, 14 and 15. Except for the aforementioned, there is no strong interrelationship between talent and total assets that significantly stands out.

Third, the categories of rows are the same as for the above two cases, hence, the categories of the columns were classified with a focus on the operating profit of the company: 1-below $\$ 0$ (loss), 2-below $\$ 400$ million, 3-below $\$ 1.6$ billion, 4-more than $\$ 1.6$ billion.

Dimension 1 had an inertia value of 0.026 and an interpretability value of about 46.2\%, whereas Dimension 2 showed an inertia value of 0.021 and an interpretability value of about $36.3 \%$. Also, Dimension 3 showed an inertia value of 0.010 and an interpretability value of about $17.5 \%$. The Chi-square value was measured at 35.249 , while $\mathrm{p}<0.13$ appeared at the degree of freedom of 66 .

It was found that talent 21: Savings and talent 23: Etiquette are considered outliers of this study. The above figure was redrawn after excluding these two factors. A significant result is that companies recorded a loss operating profit showed a slight difference compared to the companies that recorded a profit (Figure 3). Talent 12: Self-directedness has a low correlation with profit 4: more than $\$ 1.6$ billion; and talent 20: Positive attitude has relevance to only profit $1: \$ 0$. In addition to this talent 17: customer respect showed a relatively strong association with profit 3: bellow $\$ 1.6$ billion. After reducing the scale of column 1, the distinction becomes more pronounced. 

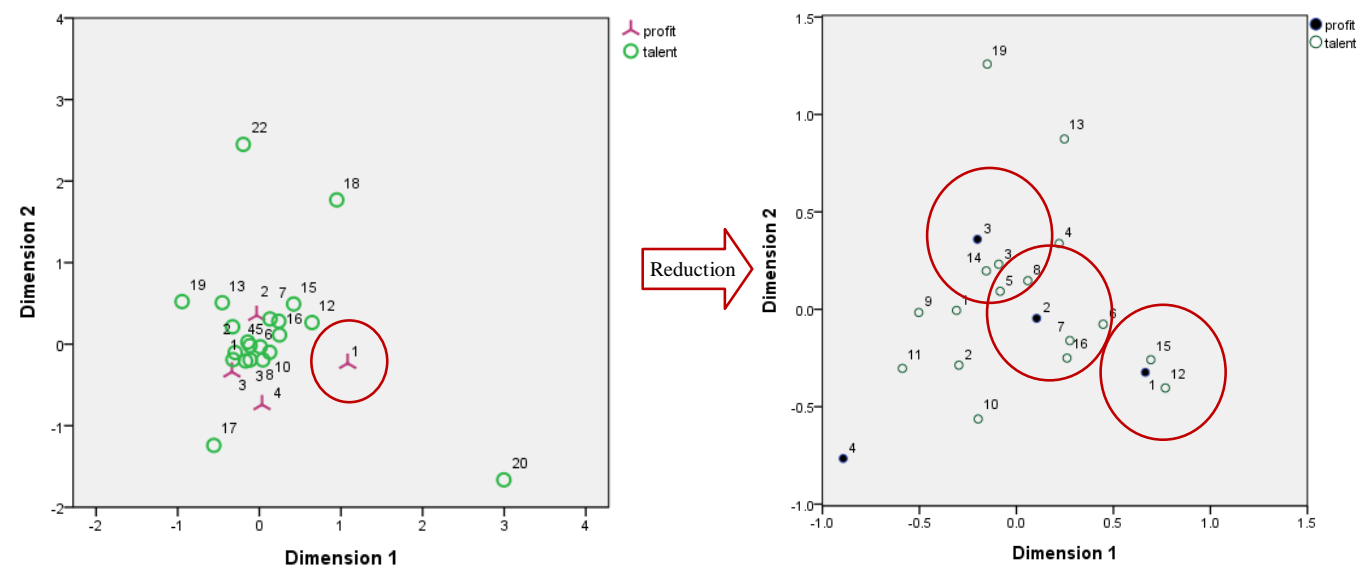

Figure 3. Correspondence Analysis Table between Operating Profit and Talent

As shown in the right chart of Figure 3, there are 2 factors, talent 12: Selfdirectedness and talent 15: Immersion, in which companies recorded a loss operating profit. Likewise, there is a profound relationship with profit $2-3$ : below $\$ 1.6$ billion and the following: talent 3: Creativity, talent 5: Morality, and talent 8: Responsibility.

The results of the analysis showed that the correspondence analysis table, in terms of the sales fluctuations, displayed similar patterns. Lastly, the regions of 100 companies were divided into: 1-Seoul, 2-Incheon and Gyeonggi Province, 3-Honam and Chungcheong Province, and 4-Yeongnam Province.

Dimension 1 had an inertia value of 0.026 and an interpretability value of about 47.5\%, whereas Dimension 2 showed an inertia value of 0.016 and value of about 28.8\%. Also, Dimension 3 showed an inertia value of 0.013 and an interpretability value of about $23.7 \%$. The Chi-square value was measured at 34.413 , while $p>0.25$ appeared at the degree of freedom of 66.

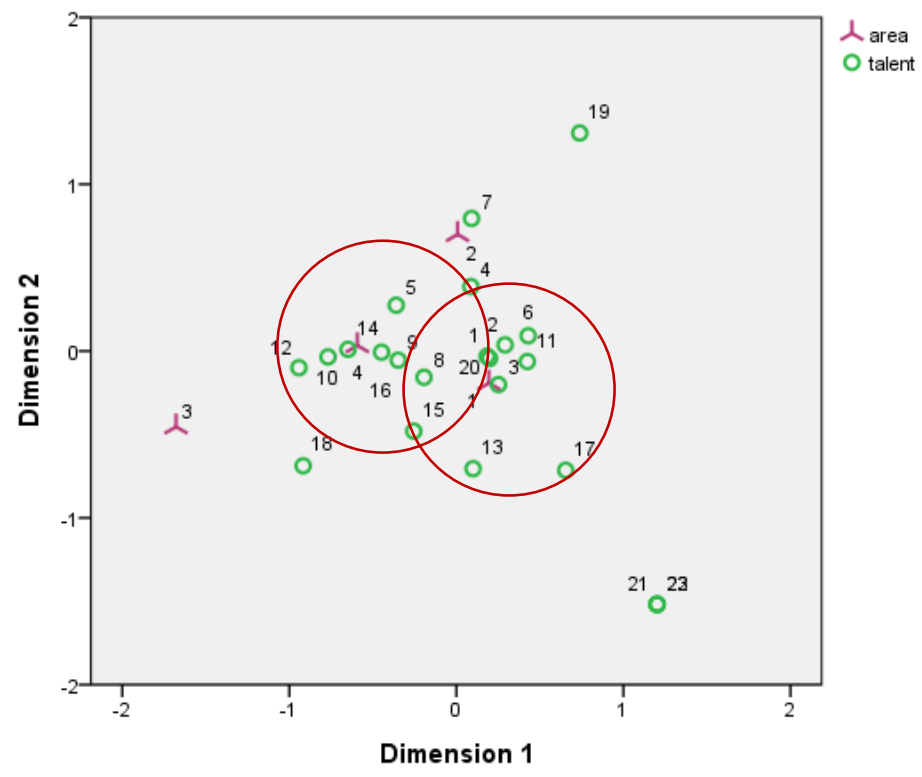

Figure 4. Correspondence Analysis Table between Area and Talent

Consequently, area 3: Honam and Chungcheong province is off slightly and the linkage between the area 1: Seoul and area 4: Yeongnam province was found to be relatively 
stable. There is also a direct correlation between talent 2: Cooperation, talent 4: Innovation, and area 2: Incheon and Gyeonggi Province. Namely, companies in area 2 prefer a cooperative and innovative person.

\section{Final Remarks}

South Korea has entered the period of low growth, so businesses are sparing no effort to foster and nurture human resources. Every company aims to sustain growth well-matched to the convergence era by cultivating human talents armed with a balanced combination of these talents and requisites [9].

On the basis of these needs, we analyzed the image of the right people of the leading domestic South Korean enterprises in this study through the R-statistic and correspondence analysis. Among the 23 factors of the right people, most of the factors, except for the specialty and insight, are conjectured to be related to human nature. This "fact" is a circumstantial evidence that humanity cannot change easier than technical skills. Above all, most of skills and knowledge can be trained for. Hence, companies tend to prefer attitude to skills. And business environment, such as area and business type, influenced the formulating an image of right people of company. Construction and Banking, Securities, \& Financial business companies prefer human resources with the elements of creativity, passion, openness, and self-directedness. And companies having more than $\$ 16$ billion but less than $\$ 32$ billion of total assets pursue creativity, morality, and interaction as factors of the right people. From a different angle, companies that record a loss in operating profit showed a large difference between the companies that recorded a profit in their image of the right people, except for self-directedness. In another dimension, companies in the Honam and Chungcheong area have a relatively weak correlation with the companies in Seoul and Yeongnam area.

In conclusion, we can offer some suggestions. First, the objectives of an education policy, a human resource development system of a company, and its detailed implementation procedures should be renovated to meet the changing demands of talented people. Education for skills and technique - not for qualifications - must be urgently improved. Moreover reorganization of employment support services, enhancing partnership between academia and the corporate world for employment, promoting internship in the curriculum of universities, remain as problems await to be solved. For this, additional research is needed about ways of fostering talented people in school and companies because human resource management has been emphasized only certain aspects of knowledge so far. So, the cultivation of very talented people places priority on inherent personality. It is also equivalent to hiring new talent, as well as the fostering of existing human resources.

Second, we can extend this study through a cost-effectiveness analysis. Comparison targeting is hiring the right people with the desired properties and training existing employees. Some research problems are which one generated a greater effect and which one costs more. The results of a cost-effectiveness analysis can determine whether a company can be focused on the other side. In other words, company can choose between strengthening staff training system and making an investment in discovering a talent.

Third, companies should be prompt in dealing with the changes of the society having uncertainty flexibly. If it is necessary, a company could make the development of human resources in establishing new image of the right people as reflecting its own vision and mission. The neglect of human resources can quickly damage a corporation. Comparisons between domestic companies and international corporations may also have significant implications. In particular, it is essential to avoid to imitate the personnel system of the global group unquestioningly and to transform while considering the environment and sentiment of own country. 
Lastly, by conducting a correspondence analysis on the demands of talents that have been changing over time from the diachronic and macro perspective, scholars and companies will be able to predict the traits of talented people who will lead the future society.

\section{References}

[1] J. Jin Lee and K. Yoon, "A Study on the Characteristics of Human Resources Required in Korean Companies", Journal of Management Education, vol. 10, (2010), pp. 71-102.

[2] Y. Seo, S. Shim, E. Kim and J. Shoi, "An Empirical Study for the Cognition of the Convergence Human Resource for the companies-focus on the Firms in Deajeon Region", Journal of the Korea AcademiaIndustrial cooperation Society, vol. 13, no. 5, (2012), pp. 2045-2053.

[3] T. You, Y. Kim, H. Kim, H. Park, Y. Shim, J. Kim, S. Kim, S. Kim and Y. Ahn, "The Content Analysis of Desirable Talent in Korean Companies", The Korean Psychological Association, (2008), pp. 264-265.

[4] S. Park, S. Oh and H. Park, "Study on meet the growing demand of human resources competency-oriented of university education", Modern society and administration, vol. 20, no. 3, (2010), pp. 171-197.

[5] E. Cho and S. Lee, "Changes in the Ideal Human Types of Korean Firms according to Environmental Changes and its Implications for Human Resource Development", The Korean Journal for Human Resource Development, vol. 6, no. 1, (2004).

[6] K. Jung, "A Study of foresight method based on text mining and complexity network analysis", KISTEP, (2010).

[7] H. Oh and E. Sung, "Competency Modeling of Convergence Talent", Journal of Asian Education, vol. 14, no. 4, (2013), pp. 201-228.

[8] C. Kim, SPSS Data Analysis, 21cbook, (2011).

[9] J. Bae and Y. Lee, "An Analysis on the Right People of Major National Companies and Policy Implications of Human Resource Development", Asia-pacific Journal of Multimedia Services Convergent with Art, Humanities, and Sociology, vol. 5, no. 1, (2015).

[10] J. Ivy, "Higher education institution image: a correspondence analysis approach", The International Journal of Educational Management, vol. 15, no. 6, (2001), pp. 276-282.

[11] K. Seo, Y. Cho and M. Sung, "A Research on the Basic Competency for Cultivating the Intelligent Persons Cognized by College Students and Personnel Managers in Enterprises", Science and Engineering Research Support Society, vol. 3, no. 1, (2014), pp. 13-22.

[12] C. S. Lacsamana, U. Tomas, J. Ganiron and T. S. Harold, "Development of Multi-Level Holistic Model in Integrated Learning", Science and Engineering Research Support Society, vol. 4, no. 1, (2015), pp. 1-10.

[13] R. Flude, "How can organizations attract the right people?, People for Business", The Key to Success International Management Series, (1991), pp.14-37.

[14] E. Kyndt, N. Govaerts, F. Dochy and H. Baert, "The Learning Intention of Low-Qualified Employees", A Key for Participation in Lifelong Learning and Continuous Training, Vocations and Learning, vol. 4, no. 3, (2011), pp. 211-229.

[15] J. M. Elegido, “Does It Make Sense to Be a Loyal Employee?”, Journal of Business Ethics, vol. 116, no. 3, (2013), pp. 495-511.

[16] L. Edward E, "Treat people right!: how organizations and individuals can propel each other into a virtuous spiral of success", San Francisco: Jossey-Bass, California, (2003).

[17] J. L.Yang, "How to Get a Job: It's brutal out there. But the people getting hired aren't necessarily the most qualified or most connected-they're the most creative", Fortune international, vol. 159, no. 7, (2009), pp. 52-59.

\section{Authors}

Ji-Hye Bae, Graduate School of the Department of Education, Kyungpook National University

Young-Min Lee, Graduate School of Human Resource Developments for Women, Sookmyung Women's University 